\title{
ZONEAMENTO GEOAMBIENTAL DA QUARTA COLÔNIA RIO GRANDE DO SUL: uma análise integrada da paisagem
}

\author{
Gerson Jonas Schirmer \\ Universidade Federal de Santa Maria, Cachoeira do Sul, RS, Brasil \\ geogersonjs@gmail.com
}

Luís Eduardo De Souza Robaina

Universidade Federal de Santa Maria, Santa Maria, RS, Brasil

lesrobaina@yahoo.com.br

\begin{abstract}
RESUMO
Este artigo apresenta o Zoneamento Geoambiental da Região da Quarta Colônia-RS, onde os sistemas geoambientais representam a integração, através da pesquisa dos elementos físicos naturais da área de estudo, frente às atividades sociais, desenvolvidas pela ocupação do meio, que transformaram a paisagem local. A metodologia é fundamentada nas contribuições da ciência geográfica, apresentando uma abordagem sistêmica da paisagem, utilizando como ferramenta SIGs (Sistemas de Informação Geográfica). Através de uma representação de síntese, foram definidos cinco Sistemas, que caracterizaram a paisagem geoambiental dos municípios que compõem a região da Quarta Colônia, definidos como: Sistema Urbano; Sistema Arrozais em Rampas de Depósitos Recentes; Sistema de Relevo Escarpado e Vegetado do Rebordo do Planalto; Sistema de Colinas de Altitudes Elevadas: com a Unidade Colinas Vulcânicas em Pequenas Propriedades, Unidade Colinas Vulcânicas em Médias Propriedades, Unidade Colinas de Altitudes em Rochas Friáveis; Sistema de Colinas em Baixas Altitudes: com a Unidade Colinas em Rochas Sedimentares de Encosta e a Unidade de Colinas Sedimentares de Baixa Altitude. Considera-se que este trabalho oferece um referencial teórico-metodológico e um conjunto de dados georreferenciados que permite verificações das potencialidades e restrições ambientais da região analisada, favorecendo a maximização de propostas de desenvolvimento sustentável.
\end{abstract}

Palavras-chave: ZoneamentoGeoambiental. Quarta Colônia. Paisagem

\section{QUARTA-COLÔNIA GEOAMBIENTAL ZONING RIO GRANDE DO SUL: an integrated analysis of the landscape}

\begin{abstract}
This article presents a Geoenvironmental Zoning of the Region of the Quarta Colônia - RS, where the geoenvironmental systems represent the integration, through the research of the natural physical elements of the study area, in front of the social activities, developed by the occupation of the environment, that transformed the local landscape. The methodology is based on the contributions of geographic science, presenting a systemic approach to the landscape using GIS (Geographic Information Systems) as a tool. Through a synthesis representation, five Systems were defined, which characterized the geoenvironmental landscape of the municipalities that compose the region of the Quarta Colônia, defined as: Sistema Urbano; Sistema Arrozais em Rampas de Depósitos Recentes; Sistema de Relevo Escarpado e Vegetado do Rebordo do Planalto; Sistema de Colinas de Altitudes Elevadas: com a Unidade Colinas Vulcânicas em Pequenas Propriedades, Unidade Colinas Vulcânicas em Médias Propriedades, Unidade Colinas de Altitudes em Rochas Friáveis; Sistema de Colinas em Baixas Altitudes: com a Unidade Colinas em Rochas Sedimentares de Encosta e a Unidade de Colinas Sedimentares de Baixa Altitude. It is considered that this work offers a theoretical-methodological reference and a set of georeferenced data that allows verifications of the potentialities and environmental restrictions of the analyzed region, favoringi the maximization of sustainable development proposals.
\end{abstract}

Keywords: Zoning. Geoenvironmental. Quarta Colônia. Land Scape

$\begin{array}{llllll}\text { Caminhos de Geografia } & \text { Uberlândia - MG } & \text { v. 19, n. } 68 & \text { Dez/2018 } & \text { p. 200-214 Página } 200\end{array}$




\title{
INTRODUÇÃO
}

O termo geoambiental tem sido utilizado para denominar estudos que contemplam aplicações dos conhecimentos técnicos do meio físico e socioeconômico, correlacionando informações sobre ambos. Segundo Vedovello (2004, p. 337), de uma forma mais ampla, a cartografia Geoambiental pode ser entendida como,

\begin{abstract}
...todo o processo envolvido na obtenção, análise, representação, comunicação e aplicação de dados e informações do meio físico, considerando-se as potencialidades e fragilidades naturais do terreno, bem como perigos, riscos, impactos e conflitos decorrentes da interação entre as ações humanas e o ambiente fisiográfico. Pode por isso, incorporar elementos bióticos, antrópicos e socioculturais em sua análise e representação. Nesta concepção, a cartografia geotécnica estaria incluída no escopo geral da cartografia geoambiental. (VEDOVELLO, 2004, p. 337)
\end{abstract}

Como exemplo da aplicação desses mapeamentos, cita-se o trabalho desenvolvido por Souza et al. (2005), o qual utiliza a cartografia geoambiental, como suporte para a elaboração do Plano Diretor Ambiental e Urbanístico de Mariana, no estado de Minas Gerais; Zoneamento geoambiental do município de São Pedro do Sul - RS elaborado por Menezes et al. (2012), a compartimentação da Bacia do rio Itu, no oeste do RS realizada por Trentin e Robaina (2012), os estudos de Calderano Filho et al. (2013), que produziram informações físico-bióticas na área de influência do Rio Grande, e o trabalho de Cabral (2014), que desenvolveu, na sua dissertação, um zoneamento geoambiental do município de Sorriso, Mato Grosso. Além disso, o zoneamento geoambiental serviu de base para o desenvolvimento do Atlas Geoambiental de São Borja elaborado por Robaina et al. (2007), Atlas Geoambiental de Agudo elaborado por Schirmer e Robaina (2010) e o Atlas Geoambiental de Manoel Viana de Robaina et al. (2014).

O Zoneamento Geoambiental fornece a organização da área em sistemas e unidades com características ambientais semelhantes quanto às potencialidades e restrições de uso e ocupação devido às condições atuais da área, referentes às características físicas e ação antrópica que constituirão sua dinâmica atual. Dessa forma, pode ser visto como um instrumento de ordenamento territorial que busca identificar as restrições e as aptidões ambientais naturais quanto ao uso e a ocupação humana, propondo uma forma harmônica de relação entre a sociedade e a natureza. Com a utilização de novas geotecnologias isto se torna mais simplificado, pois se tem a possibilidade de sobrepor, cruzar e integrar informações de maneira rápida e automatizada.

Assim, o presente trabalho apresenta um zoneamento, baseado em cruzamento temáticos, utilizando geotecnologias, que permite estabelecer áreas com limitações e potencialidades, podendo servir de subsídio ao planejamento e a atuação ambiental na região da Quarta Colônia-RS.

\section{PROCEDIMENTOS TEÓRICO-METODOLÓGICOS}

A delimitação da área de trabalho usa como base o que foi definido, em 1996, quando foi criado o Consórcio de Desenvolvimento Sustentável da Quarta Colônia (CONDESUS/Quarta Colônia), formado por nove municípios da Região Central do Rio Grande do Sul. Este consórcio é administrado pelos prefeitos dos municípios envolvidos com o apoio de uma Secretaria Executiva. Os municípios que compõem essa região são: Agudo, Dona Francisca, Faxinal do Soturno, Nova Palma, Pinhal Grande, São João do Polêsine, Restinga Seca, Ivorá e Silveira Martins (Figura 1).

A região da Quarta Colônia possui uma diversidade fisionômica da paisagem, sendo representada pelas regiões geomorfológicas da Depressão Periférica, passando pelo Rebordo do Planalto e chegando ao início do Planalto das Araucárias (ZERFASS, 2007). O relevo escarpado com paredões e vales encaixados com cachoeiras e grutas destacam as belezas naturais. No aspecto cultural ganham destaque a gastronomia e arquitetura das igrejas e das moradias, que caracterizam as culturas italiana e alemã. A ocupação agrícola dessa região desde seu início vem gerando conflitos ambientais por não respeitar as áreas com restrições ambientais.

$\begin{array}{llllll}\text { Caminhos de Geografia } & \text { Uberlândia - MG } & \text { v. 19, n. } 68 & \text { Dez/2018 } & \text { p. 200-214 } & \text { Página } 201\end{array}$


Figura 1: Mapa com localização da áreas de estudo

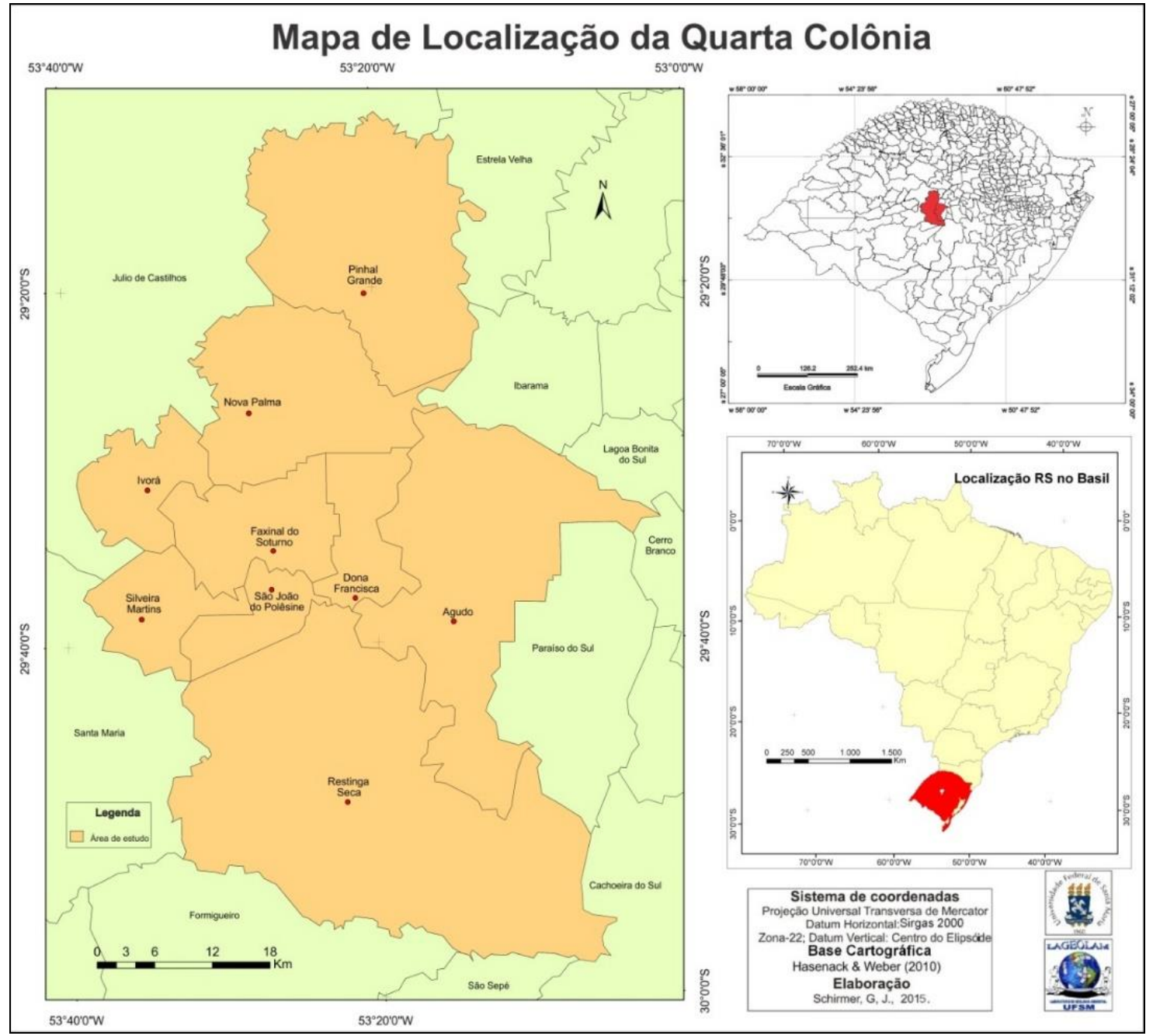

Fonte: Autor.

A elaboração do Zoneamento Geoambiental tem como premissa a compartimentação da paisagem com base nas características do geoambiente e suas inter-relações com as atividades antrópicas, colocando em evidência as suas potencialidades e restrições de uso, a partir de áreas com maior homogeneidade. A metodologia utilizada parte de uma abordagem sistêmica, proposta por Bertalanffy (1976), conforme se observa na (Figura 2).

$\mathrm{Na}$ execução desta pesquisa, foram adotadas concepções de cartografia geoambiental adotadas por Zuquette (1987e 1993), seguindo metodologias aplicadas por De Nardin (2010), Robaina et al. (2010), Robaina (2010) e Trentin (2011).

O trabalho desenvolveu-se a partir de um banco de dados topográficos do Rio Grande do Sul (1:50.000) (HASENACK e WEBER, 2010), no formato shapefile, para elaboração de mapas temáticos que serviram de base para a elaboração do zoneamento, foi utilizado o Arc Gis 10.1. Para a confecção do mapa de uso da terra utilizou-se como base de recobrimento da área, a imagem orbital do sensor "OLI" do LANDSAT-8, bandas 543(R, G, B) de composição colorida, com 30 metros de resolução espacial, Órbita-Ponto 222/80 e 222/81, de 09 de setembro de 2014. Essas imagens foram adquiridas através do catálogo de imagens da NASA no site: http://glovis.usgs.gov/. A classificação da imagem foi realizada no aplicativo SPRING 4.3, devido a confiabilidade e ao bom resultado apresentado para este tipo de operação. Posterior a essa classificação o mapa de uso foi 
transformado em vetor e importado no formato Shapefile no aplicativo Arc Gis para realizar cruzamentos e integração de informações.

Figura 2: Visão sistêmica do Zoneamento Geoambiental.

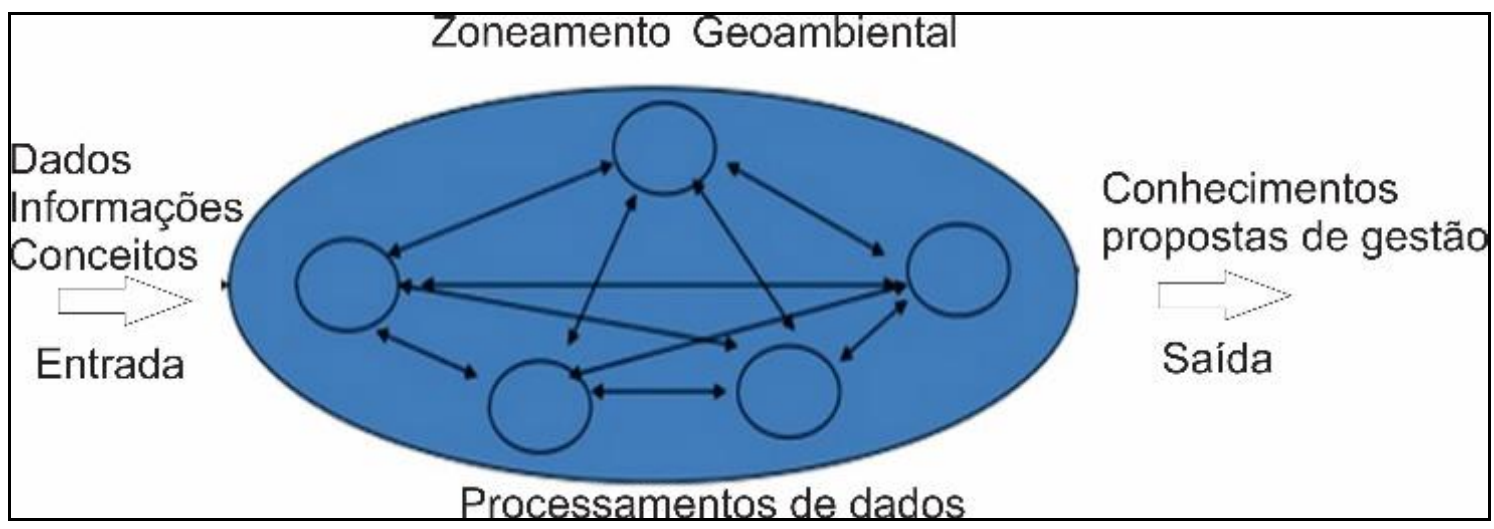

Fonte: Autor.

$\mathrm{Na}$ divisão geoambiental se utiliza um grupo de atributos para formar um sistema ou uma unidade, que são a base para a análise de uma área. Define-se como atributo o elemento base que será inserido e manuseado sobre um documento cartográfico, como informação que representa parte dos componentes do ambiente. A exemplo disso, destaca-se: os componentes do relevo, componentes pedológicos, componentes litológicos, hidrografia, geomorfologia e uso e ocupação da terra. Destaca-se que que essas informações, bem como os mapas tem éticos que serviram de base para o zoneamento foram coletadas por Schirmer (2015), durante a elaboração da tese de doutorado a qual esse artigo baseia-se.

\section{COMPARTIMENTAÇÃO DOS SISTEMAS E UNIDADES GEOAMBIENTAIS}

A definição dos sistemas geoambientais ocorreu a partir dos domínios geomorfológicos existentes na área de estudo e a relação destes com o uso e ocupação. Cada sistema apresenta heterogeneidade entre si e é possível separar algumas áreas distintas dentro de alguns sistemas, principalmente em relação à restrição e potencialidade de uso existente. Estas restrições e potencialidades tem em alguns casos maior contribuição da geologia, outras vezes dos solos e/ou do relevo.

O mapa geoambiental, mostra a espacialização hierárquica distribuída em Sistemas e Unidades, com suas principais características, a fim de definir as condições de restrições ambientais, limitações de uso e as consequentes aptidões ambientais de cada área.

Os estudos realizados possibilitaram determinar 5 principais sistemas geoambientais definidos como: Sistema Urbano; Sistema Arrozais em Rampas de Depósitos Recentes; Sistema de Relevo Escarpado e Vegetado do Rebordo do Planalto; Sistema de Colinas de Altitudes Elevadas, o qual apresenta as seguintes unidades: Unidade Colinas Vulcânicas em Pequenas Propriedades, Unidade Colinas Vulcânicas em Médias Propriedades, Unidade Colinas de Altitudes em Rochas Friáveis; Sistema de Colinas em Baixas Altitudes, apresentando as seguintes unidades: Unidade Colinas em Rochas Sedimentares de Encosta e a Unidade de Colinas Sedimentares de Baixa Altitude, como pode ser visualizado na (Figura 3). 
Figura 3: Mapa com Zoneamento Geoambiental da Quarta Colônia.

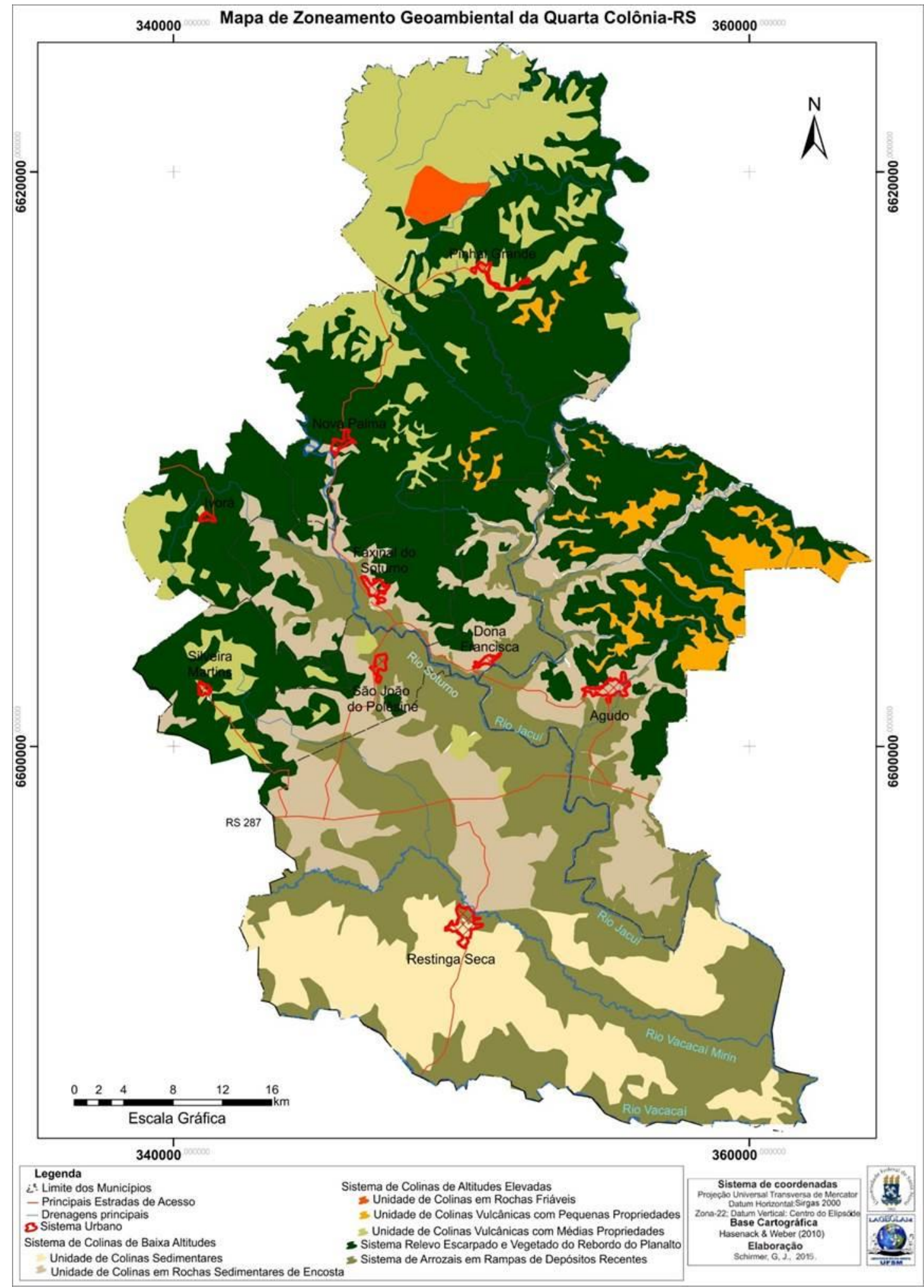

Fonte: Autor. 


\section{SISTEMA URBANO}

O sistema urbano da Quarta Colônia-RS (Figura 4) é composto por nove cidades sedes dos municípios exercendo um papel centralizador com relação ao oferecimento de bens e serviços necessários a sua comunidade.

Figura 4: Cidades da Quarta Colônia.
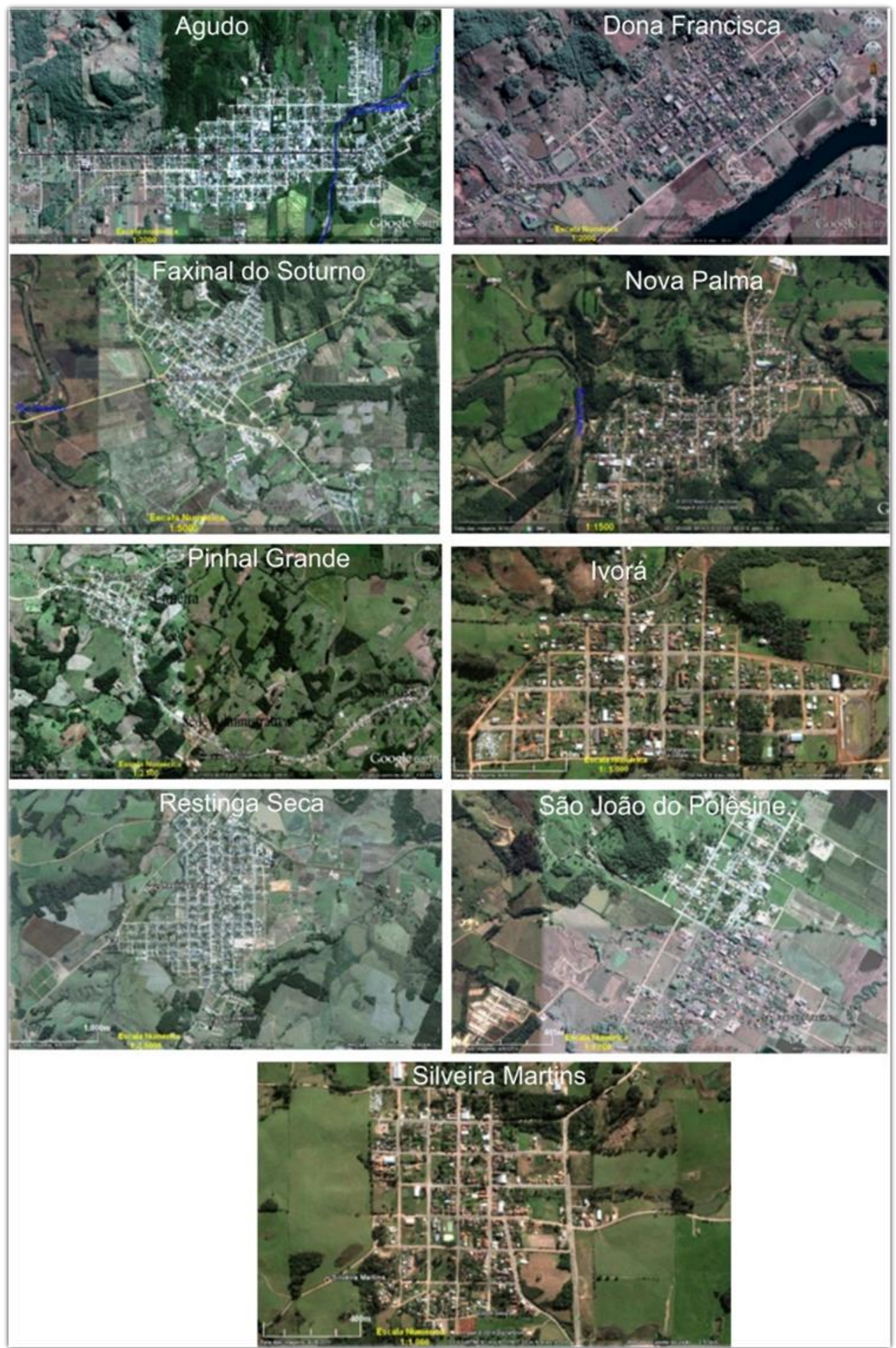

Fonte: Google Earth, imagem 2011. 
O sistema Urbano está caracterizado por cidades com uma população variando de 8.982 habitantes em Restinga Seca, 6.889 habitantes em Agudo e 4.115 habitantes em Faxinal do Soturno que são as maiores e nas menores a população é de: 2.146 habitantes em Dona Francisca, á 850 habitantes no município de Ivorá.

Nos últimos anos houve uma significativa migração de mão de obra do espaço rural gerando um decréscimo de $10 \%$ da população rural e um acréscimo de, aproximadamente, $20 \%$ da população urbana, de acordo com interpretações realizadas a partir de dados do censo do (IBGE, 2010). Nesse sentido, as cidades tem um papel fundamental de absorver esta mão de obra. Porém, a falta de uma política habitacional e a deficiente infra-estrutura urbana tem causado sérios proemas de poluição de cursos d'água e de riscos associados processos fluviais e de encosta.

As cidades localizadas no Planalto ocorrem assentadas em substrato de vulcânicas e as localizadas ao sul em substrato de rochas sedimentares. As principais fragilidades estão relacionadas ao avanço de ocupações ao longo dos cursos d'água, especialmente Restinga Seca, Nova Palma, Dona Francisca e Ivorá e em direção a áreas de encosta íngreme como acontece em Agudo e Nova Palma. Além disso, deve-se considerar um importante conflito ambiental: a degradação dos cursos d'água que cruzam as cidades. O tratamento de esgotos é deficitário e a ocupação das margens é comum.

\section{SISTEMA PLANÍCIE DE ARROZAIS EM RAMPAS DE DEPÓSITOS RECENTES}

Neste sistema, ocorrem os depósitos recentes de planície de inundação (Quaternário), localizados próximos ao canal principal dos rios e aos seus afluentes, os solos são mal drenados. Com relação às formas do relevo, estas áreas são definidas como rampas de baixas altitudes e apresentam declividades menores que $5 \%$.

Ao longo dos canais principais resta ainda, em algumas porções, uma pequena faixa de mata ciliar, onde as espécies vegetais mais características são o Sarandi (Sebastiania schottiana), o Coqueiro-gerivá (Syagrus romanzoffiana), o branquilho (Sebastiana commersoniana), a Pitangueira (Eugenia uniflora), o camboatá-branco (Matayba elaeagnoides), a Aroeira-cinzenta (Schinus lentiscifolius), a Capororoca (Rpanea lorenziana), o Angico vermelho (Parapiptadenia rígida), Guajuvira (Patagonula americana), Canela do brejo (Machaerium stipitatum) e o Grápia (Apuleia leiocarpa). Estas espécies vegetais foram identificadas através de trabalhos de campo realizados durante a pesquisa.

A principal atividade desenvolvida é o cultivo de arroz, que se associa à disponibilidade hídrica e potencialidade do solo. Grandes áreas alagadas, onde antes havia banhados, conhecidos localmente como ceival ou banhadão, foram drenadas ou aterrados para o plantio de arroz.

A maior fragilidade deste sistema está associada a compactação do solo e à mata ciliar, que vem sendo retirada nas últimas décadas de maneira muito agressiva, dando lugar para o desenvolvimento da agricultura. Os banhados que ainda restam tornaram-se impróprios para vida aquática devido ao uso indiscriminado de agrotóxicos, principalmente nas lavouras de arroz. A vegetação arbórea ao longo do canal do rio Jacuí, em sua grande maioria, não se mantém, dentro das áreas de proteção exigidas pela legislação ambiental, apenas em pequenas porções de margem do canal principal dos arroios e do Rio Jacuí, sem continuação, como se sugere em um corredor ecológico (Figura 5). 
Figura 5: Margens rio Jacuí vista da Pista de Asa-Delta em Agudo.

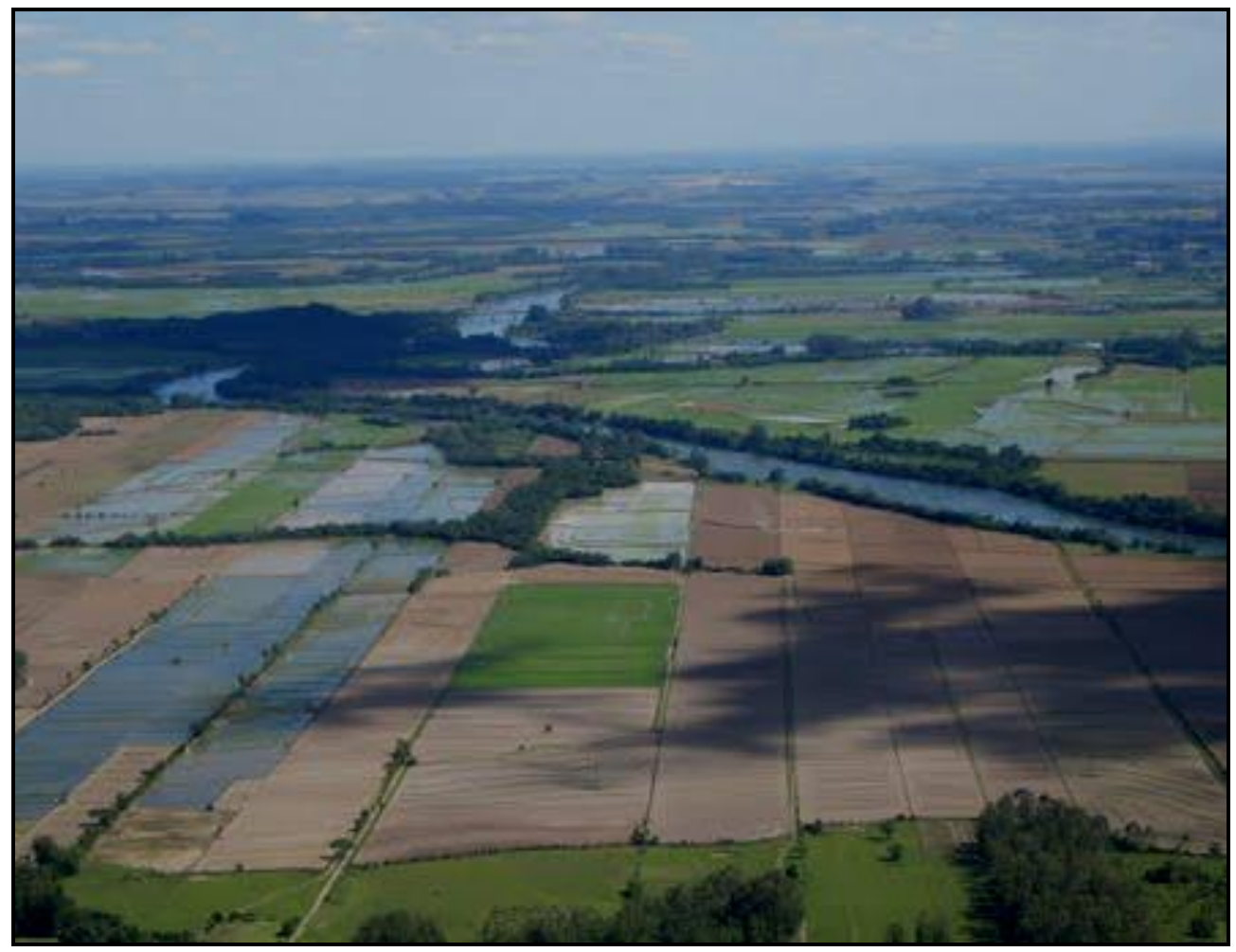

Fonte: Autor

\section{SISTEMA DE RELEVO ESCARPADO DO REBORDO DO PLANALTO}

Esse sistema indica a porção de transição entre a Depressão Periférica e o Planalto da Serra Geral. As declividades predominantes nesse sistema são superiores a $15 \%$, formado por um relevo com formas de morros e morrotes. Este sistema apresenta como principal característica da paisagem formas dissecadas, com drenagens encaixadas.

As declividades variam de 5 a $15 \%$ nos pequenos patamares entre-escarpa existente nos contatos de derrames ou de diferentes litologias e superiores a 15\% nas demais porções, manifestando processos de dinâmica superficial como erosão, rolamento, corrida e queda de blocos.

Através de trabalhos de campo foram definidas como litologias predominantemente, de arenitos eólicos e rochas vulcânicas. Os solos são rasos, constituindo, predominantemente por uma associação de Cambissolos, Neossolos litólicos, afloramentos de rocha, além de depósitos de colúvios.

É possível observar-se conflitos ambientais nessa área, relacionados aos cortes rasos da vegetação para uso da lenha como fonte de energia nas estufas de fumo. Isso ocorre nas encostas com declividade acima de $47 \%$, onde o uso possui restrições legais segundo a legislação. Essas áreas normalmente estão associadas à área central da Reserva da Biosfera da Mata Atlântica, onde não é permitido o corte da vegetação. Essa unidade possui um grande potencial turístico natural, composto por paredões, cascatas, cachoeiras, grutas e belezas cênicas da paisagem em si (Figura 6).

O uso é restrito devido ao relevo, ocorrendo somente pequenas áreas com atividade agrícola e pecuária, nos patamares entre-escarpas.

$\begin{array}{llllll}\text { Caminhos de Geografia } & \text { Uberlândia - MG } & \text { v. 19, n. } 68 & \text { Dez/2018 } & \text { p. 200-214 } & \text { Página } 207\end{array}$


Figura 6: Relevo escarpado típico do Rebordo do Planalto, na pista de salto de paraglide, em Agudo.

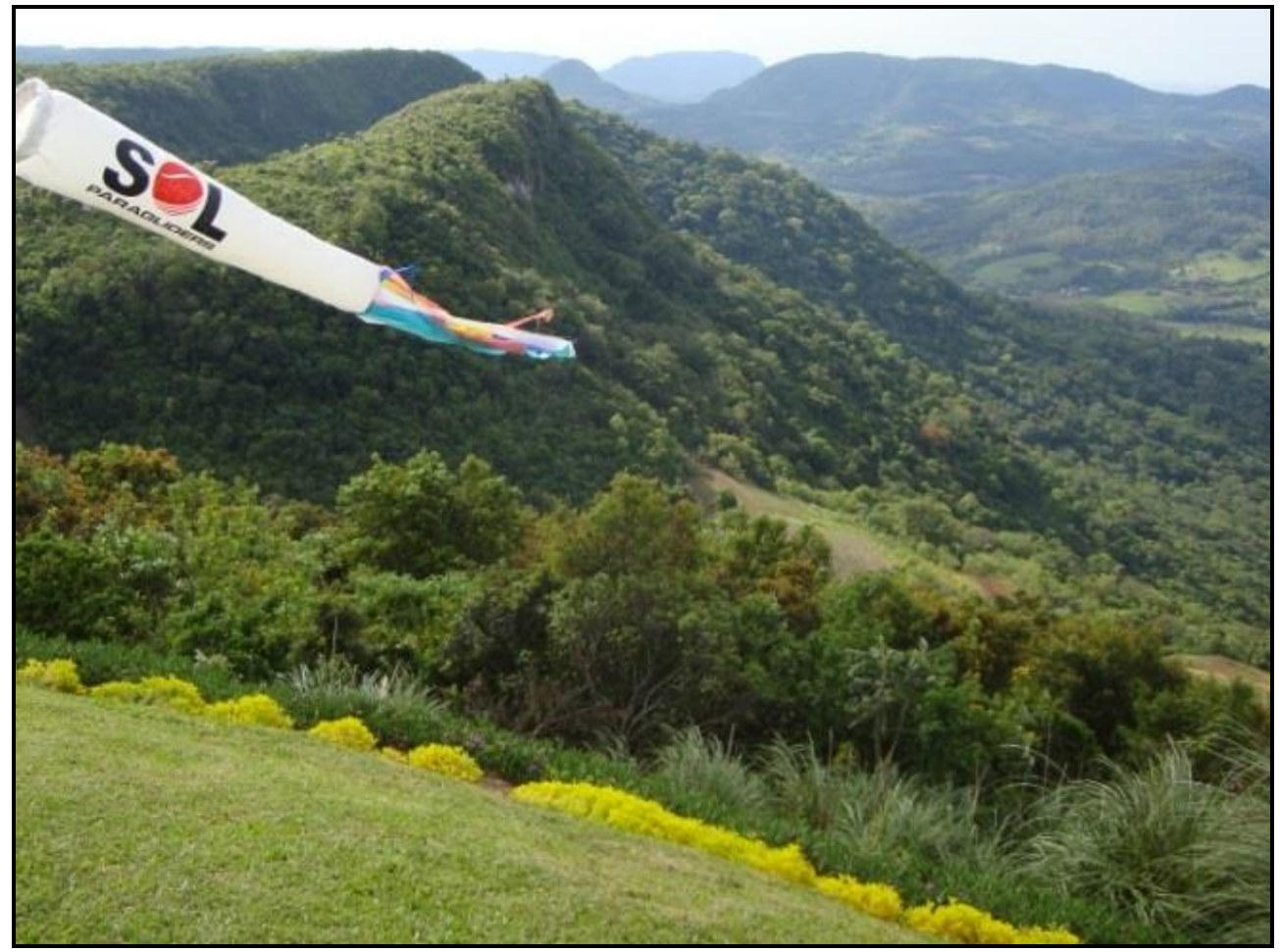

Fonte: Autor.

\section{SISTEMA DE COLINAS DE ALTITUDES ELEVADAS}

Este sistema caracteriza-se por apresentar relevo ondulado a suavemente ondulado localizado nas maiores altitudes da área de estudo. Os processos superficiais que ocorrem sobre esse sistema, associadas as características do substrato rochoso que as mantém, e as características de propriedade da terra, definiu uma divisão em 3 unidades.

\section{UNIDADE DE COLINAS DE ALTITUDE EM ROCHAS FRIÁVEIS}

Esta unidade é exclusiva do município de Pinhal Grande, localizando-se na porção norte do município. Encontra-se acima de 300 metros de altitude em declividades entre 5 e 15\%, configurando um relevo ondulado a levemente ondulado. Está assentada sobre arenitos conglomeráticos da Formação Tupanciretã, solos classificados como Argissolos arenosos (Figura 7).

Os usos com atividades agrícolas nessa área são o cultivo de soja, trigo e pecuária (ovina e de gado de corte). Há grande fragilidade natural encontrada nessa área por estar sobre arenitos friáveis e com solos arenosos e espessos, com baixo percentual de ligantes. Apresenta processos erosivos lineares, com presença de voçorocas, ravinas e "pipings". 
Figura 7: Rebanho de Gado e voçoroca próximo ao topo da colina.

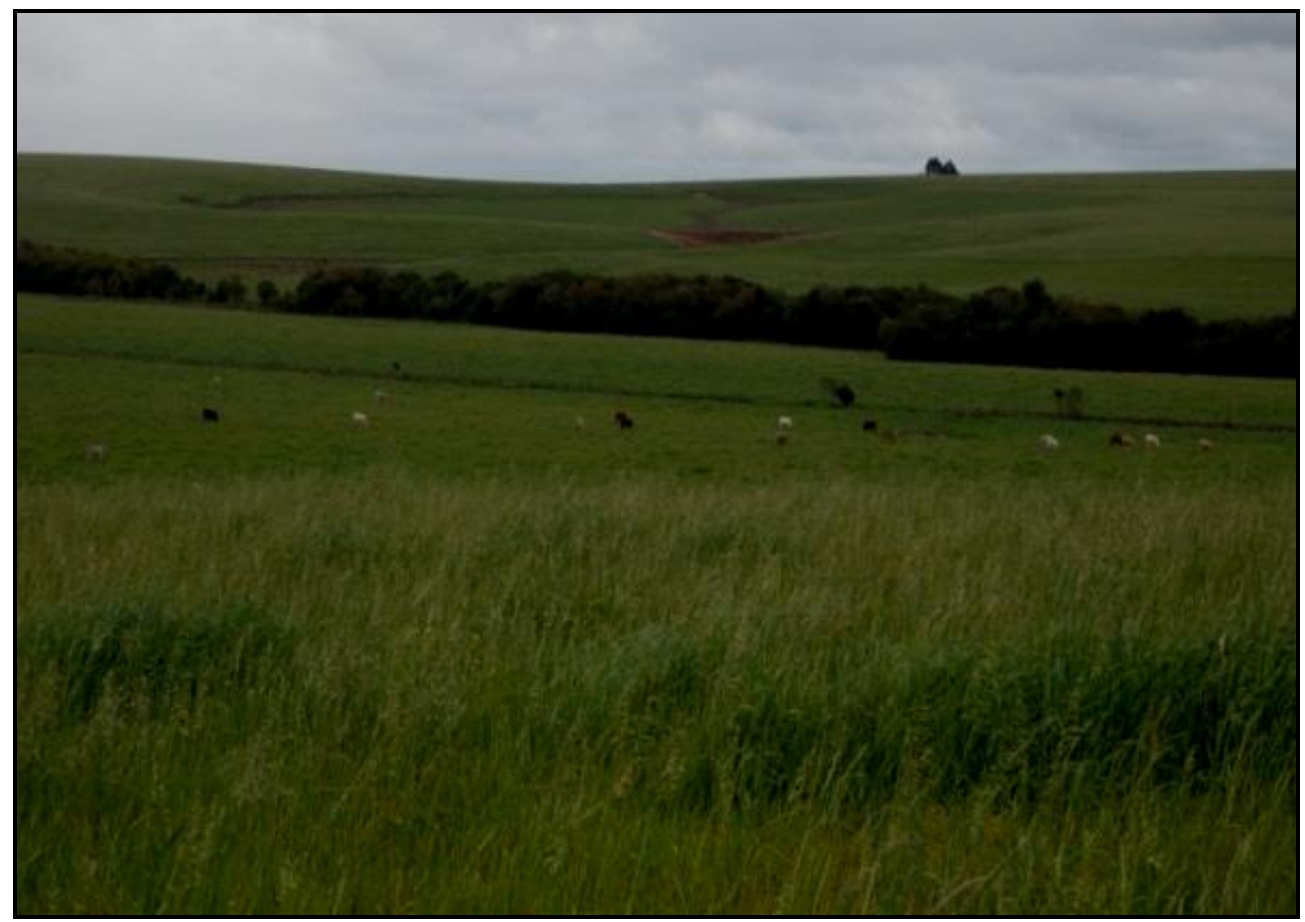

Fonte: Autor.

\section{UNIDADE DE COLINAS VULCÂNICAS EM PEQUENAS PROPRIEDADES}

Esta Unidade localiza-se nos municípios de Agudo, Dona Francisca, Faxinal do Soturno e no leste Nova Palma e Pinhal Grande. Encontra-se em declividades inferiores a 15\%, apresentando relevo ondulado de altitudes superiores a 400 metros, assentada sobre rochas vulcânicas, solos classificados como Argissolos, avermelhados e profundos, ou Cambissolos nas áreas onde a declividade se aproxima de $15 \%$.

Os topos, nessa área, são ondulados a suavemente ondulado, favorecendo o processo de meteorização. A unidade apresenta significativa presença de mata de araucária, se comparada a outros locais da área de estudo, apresentando-se por vezes espalhadas dentro de potreiros e próximo das moradias.

O processo de ocupação inicial é que caracteriza essa unidade quanto aos tipos de usos. A colonização deu-se por lotes de no máximo duas colônias de terra (48ha), que com o passar do tempo foram sendo reduzidas com processo de divisão das terras em heranças. Predomina, assim, a pequena propriedade, entre 10 e $30 \mathrm{ha}$, onde o investimento em implementos agrícolas mecanizados torna-se quase inviável, pois não se consegue produzir para que sobre uma margem significativa de lucro para manter a propriedade. Sendo assim predomina a força de trabalho manual, animal e pequenos tratores.

Os principais usos com atividades agrícolas nessa área são o cultivo do fumo, pecuária para subsistência, cultivo de pequenas lavouras de soja e milho. Esses usos são possíveis devido ao potencial agrícola resultante do solo e do relevo da unidade.

Os impactos verificáveis dizem respeito ao corte da vegetação nativa substituído por exótica para ser usado como fonte de energia. Essa atividade deve ser controlada para que não haja uso excessivo do solo com cultivo de exótica.

Além disso, a área compreende um divisor d'água, onde localizam-se as cabeceiras de drenagem e o uso de agrotóxico tende a escoar diretamente para as nascentes, consequentemente contaminando as microbacias. As principais potencialidades que se destacam no local dizem respeito ao solo propício para a agricultura e a paisagem aliada a organização resultante da cultura local, (figura 8).

$\begin{array}{llllll}\text { Caminhos de Geografia } & \text { Uberlândia - MG } & \text { v. 19, n. 68 } & \text { Dez/2018 } & \text { p. 200-214 Página } 209\end{array}$


Figura 8: Colinas Vulcânicas em Agudo, foto A com moradias e potreiros e foto B com cultivo de fumo e eucalipto
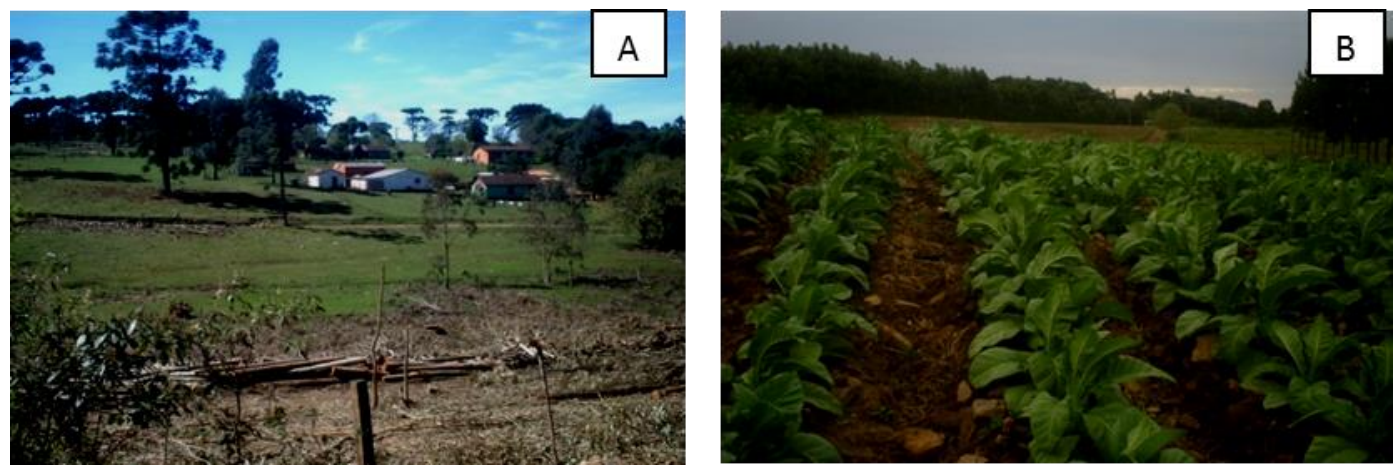

Fonte: Autor.

\section{UNIDADE DE COLINAS VULCÂNICAS EM MÉDIAS PROPRIEDADES}

Esta unidade está localizada no município de Pinhal Grande, Nova Palma, Ivorá, Silveira Martins, São João do Polêsine e Restinga Seca. Morfométricamente é caracterizada por estar em altitude, predominantemente, superior a 200 metros e apresentar declividades entre 5 e 15\%. Está assentada sobre rochas vulcânicas com solos formados por uma associação de Cambissolos e Neossolos em porções de centro de derrame e associação de Cambissolos e Argissolos em posição de topo/base de derrames.

A ocupação, predominantemente, composta por médias propriedades (50 a 300 ha) permite que se tenham cultivos agrícolas que utilizem implementos agrícolas mecanizados, por apresentar extensas lavouras de soja, de feijão, de trigo e de milho, além da significativa existência da pecuária de corte, (figura 9).

Figura 9: Fota A, Colina com forrageiras em Pinhal Grande e foto B, cultivo de Soja e Eucalipto em Ivorá.
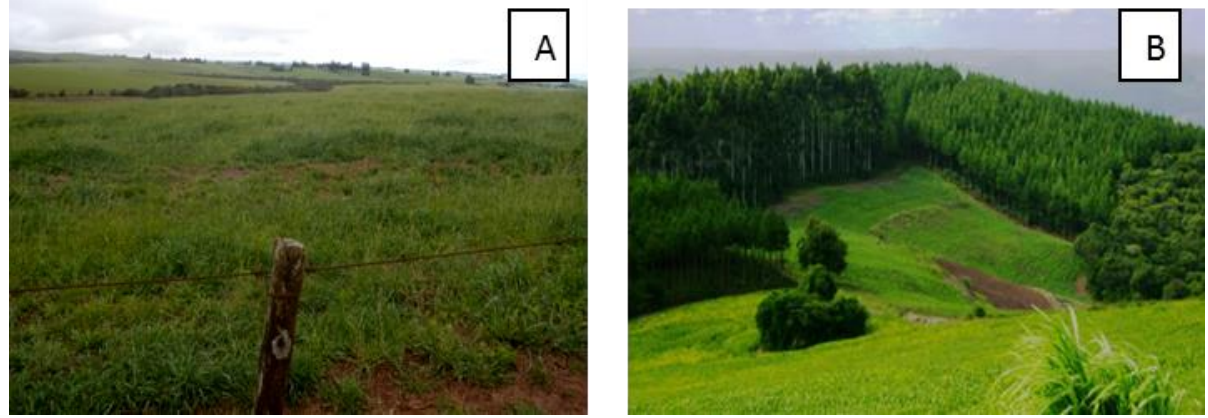

Fonte: Autor.

A principal fragilidade natural está relacionada com a existência de solos rasos com afloramentos de rochas o que dificulta as atividades agrícolas. Esses solos quando erodidos logo afloram a rocha matriz. Além disso, o uso de agrotóxico nessa área pode afetar um ampla área no local e a jusante , pois nessa unidade encontram-se significativos números de cabeceiras de drenagens. No entanto, o uso com cuidados como plantio direto possibilita boa produção agrícola.

$\begin{array}{llllll}\text { Caminhos de Geografia } & \text { Uberlândia - MG } & \text { v. 19, n. } 68 & \text { Dez/2018 } & \text { p. 200-214 } & \text { Página } 210\end{array}$




\section{SISTEMA DE COLINAS DE BAIXA ALTITUDE}

Este Sistema ocorre nos Municípios de Agudo, Dona Francisca, Faxinal do Soturno, Nova Palma, Ivorá, São João do Polêsine, Restinga Seca e Silveira Martins. De acordo com suas características singulares foi possível dividi-lo em duas unidades.

\section{UNIDADE DE COLINAS COM ROCHAS SEDIMENTARES EM BAIXA ALTITUDE}

Esta unidade (Figura 10) é exclusiva do município de Restinga Seca, localizando-se na porção sul do município, em altitudes menores de 220 metros, e em declividades predominantemente inferiores a $30 \%$. Nessas colinas encontram-se as litologias Arenito Micáceo e Arenito Buraco Fundo, que são muito friáveis. Os solos são classificados como Argissolos, mas ocorrem Neossolos quartzarênicos, sobre substrato de rochas muito quartzosas. Os usos nessa unidade estão relacionados a atividade pecuária e ao cultivo de soja. Verifica-se a presença significativa de ravinas e voçorocas de grande intensidade. A maior voçoroca dessa unidade, denominada buraco fundo, tornou-se um atrativo turístico e ponto para estudos acadêmicos.

Figura 10: Foto A, voçoroca do Buraco Fundo e foto B ( Fonte:Google Earth), marca de ravinas com vegetação no entorno

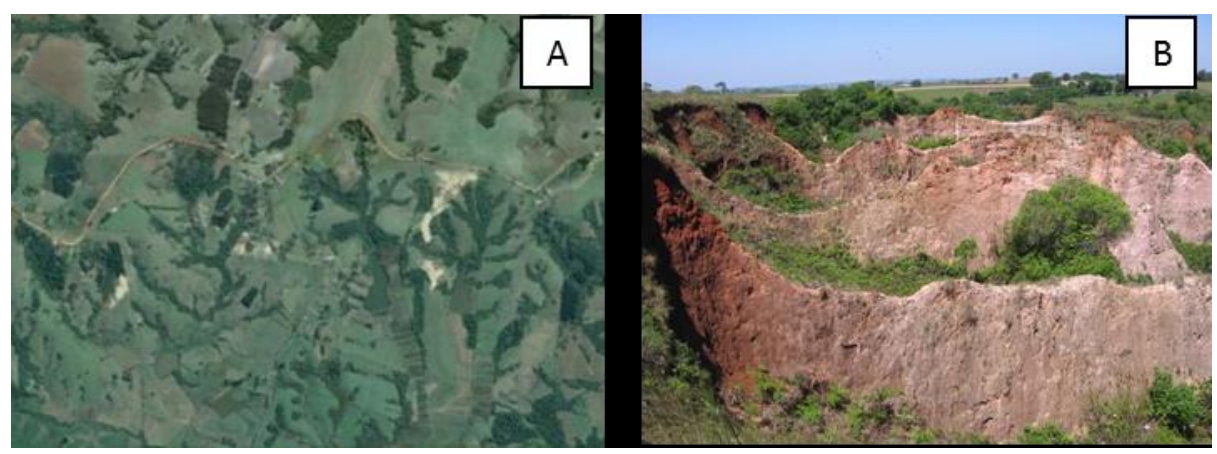

Fonte: Autor.

\section{UNIDADE DE COLINAS EM ROCHAS SEDIMENTARES DE ENCOSTAS}

Essa unidade compreende uma faixa de transição entre as rampas de baixa altitude, onde ocorre a planície de arrozais, e a porção mais dissecada do rebordo do planalto. A declividade varia entre 5 e $15 \%$, estendendo-se em altitudes superiores a 40 metros e inferiores a 180 metros. Os solos predominantes nessa unidade compreendem os Argissolos, e em porções onde o solo é mais raso desenvolve-se Cambissolos.

Neste sistema ocorrem depósitos de Colúvio-alúvio e o substrato sobre o qual está assentado varia nas diferentes porções altimétricas. Nas porções altimétricas entre $40 \mathrm{~m}-140 \mathrm{~m}$ ocorre um arenito fluvial lamítico, acima de $120 \mathrm{~m}$ ocorre em contato com rocha vulcânica e, em alguns casos, com pequenas porções de arenito eólico.

Os principais usos dessa área estão associados à pecuária de subsistência, cultivo do fumo e outros cultivos agrícolas, em sua grande maioria para subsistência. Nesse sistema encontram-se significativo número de moradias que estão no meio rural.

A principal fragilidade da unidade está associada ao lançamento de dejetos e uso de agrotóxicos nas drenagens, principalmente do cultivo de fumo. Por localizar-se próxima da encosta e em sua grande maioria sobre arenito, ocorrem inúmeras surgências que acabam por ser afetadas pela ação antrópica. Essa característica também pode trazer processos de ravinamentos onde os usos não são manejados adequadamente. Além disso, a vegetação nessa área foi reduzida a pequenos capões e uma estreita faixa nas matas ciliares.

$\begin{array}{llllll}\text { Caminhos de Geografia } & \text { Uberlândia - MG } & \text { v. 19, n. } 68 & \text { Dez/2018 } & \text { p. 200-214 } & \text { Página } 211\end{array}$


Nas imagens de satélite e trabalhos in loco foi possível perceber o elevado número de açudes existentes nessa área, o que indica um grande potencial hídrico para atividade de piscicultura. Além disso, os solos são propícios para o uso agrícola, com cuidados para controle dos processos erosivos (Figura 11). A seguir tem-se o quadro $7 \mathrm{com}$ a síntese das características dos Sistemas e Unidades Geoambientais da região da Quarta Colônia.

Figura 11: Colinas em rochas sedimentares no município de Agudo.

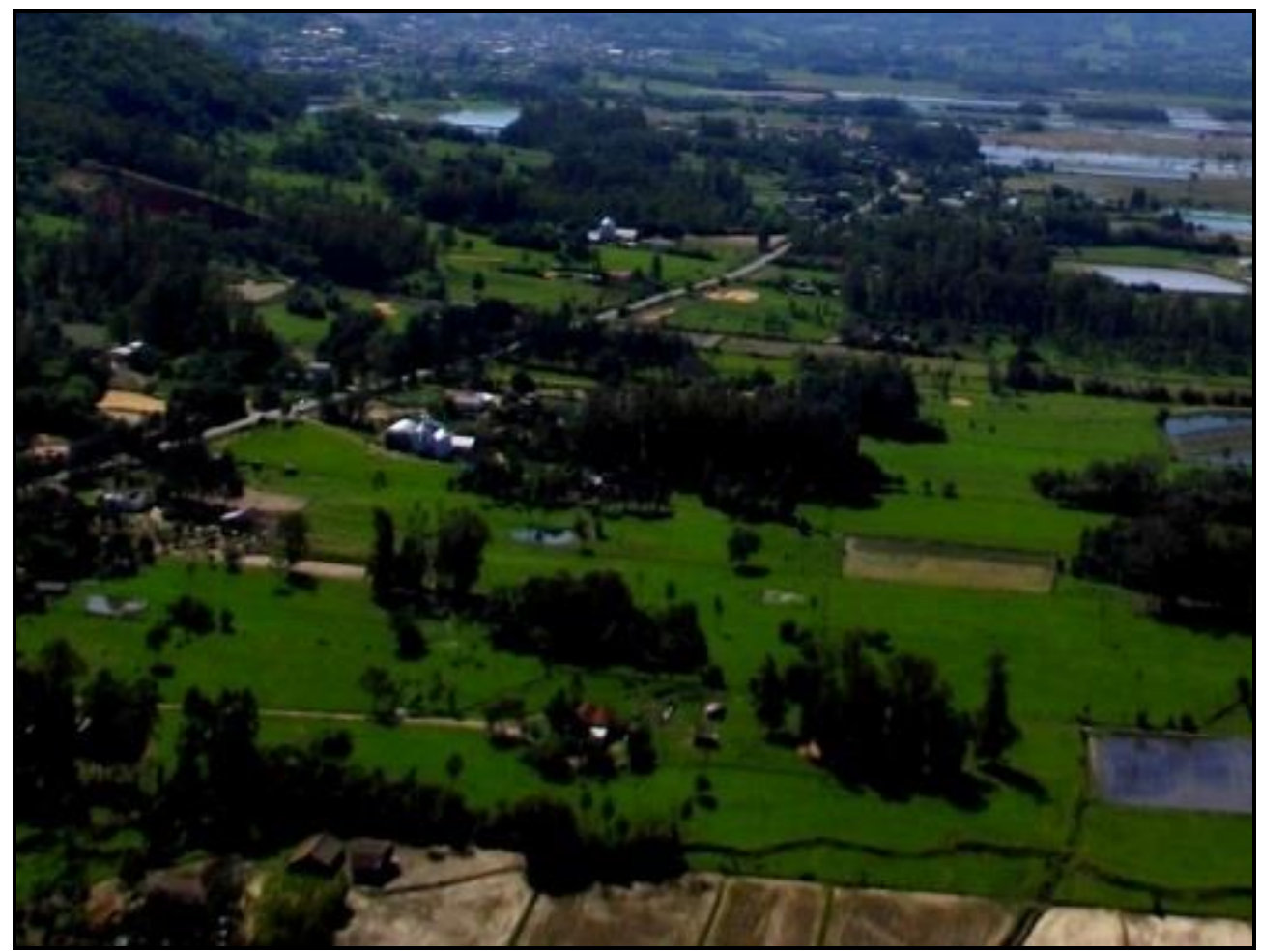

Fonte: Autor.

\section{CONSIDERAÇÕES FINAIS}

O Zoneamento Geoambiental na região da Quarta Colônia-RS, permitiu uma análise integrada dos elementos naturais da paisagem e do uso e ocupação da terra, visando definir áreas com restrições de uso e áreas com potencialidades ambientais para uso.

No que se refere a análise integrada dos elementos da paisagem, destaca-se que o Zoneamento Geoambiental e o seu estudo é uma das demandas que possibilita dialogar com a Geografia Humana e Física como una, por permitir espacializar os fenômenos da paisagem através da Cartografia.

Entre os sistemas geoambientais definidos, os que apresentam grande restrição de uso referem-se ao Sistema de Relevo Escarpado e Vegetado do Rebordo do Planalto, que comporta uma área com declividades acentuadas, onde podem ocorrem movimentos de massa; as Colinas de Altitudes em Rochas Friáveis onde o substrato geológico e solos arenosos muito friáveis, possibilitam a grande ocorrência de processos erosivos lineares. Essas características dificultam ou até mesmo impossibilitam o uso de atividades agrícolas, principalmente com maquinários. Percebeu-se na elaboração do Zoneamento Geoambiental, que as ocupações, nem sempre consideram as restrições de uso impostas pela paisagem.

$\begin{array}{llllll}\text { Caminhos de Geografia } & \text { Uberlândia - MG } & \text { v. 19, n. } 68 & \text { Dez/2018 } & \text { p. 200-214 } & \text { Página } 212\end{array}$


Na Quarta Colônia, com a modernização da agricultura e seu pacote tecnológico, aconteceram mudanças nas técnicas de produção, como uso de insumos externos químicos, mecanização e tecnificação agrícola. Com isso, aumentou a degradação do meio ambiente. Faz-se necessário verificar os impactos negativos resultante desses acontecimentos, visando garantir a qualidade de vida das novas gerações.

Cabe aos órgãos públicos elaborarem projetos que atendam às necessidades da população e de acordo com a aptidão ambiental de cada porção do território e para isso necessita informações sobre as características ambientais apresentadas de forma especializada. Portanto, esse trabalho pode ser utilizada como base para estudos e análises de detalhes.

\section{REFERÊNCIAS}

ROBAINA,L.E.S Zoneamento Geoambiental no Oeste do Rio Grande do Sul: Ferramentas para Planejamento e Gestão. A sustentabilidade da Região da Campanha-RS : práticas e teorias a respeito das relações entre ambiente, sociedade, cultura e políticas públicas. Programa de PósGraduação em Geografia e Geociências, Departamento de Geociências, Ed. 1a, Santa Maria-RS, 226 pág, 2010.

ROBAINA,LE.S. et al. Atlas Geoambiental de São Borja. 01 ed. Universidade Federal de Santa Maria: LAGEOLAM, Santa Maria, 2007, 64p.

ROBAINA,L.E.S; TRENTIN, R.; ALVES, F.da S.;. SCCOTI, A. A. V. Série atlas municipais: atlas geoambiental de Manoel Viana/RS. Organizadores. - Bagé: Ediurcamp, 2014.93p. 1DVD.

SCHIRMER,G.J.; ROBAINA,L.E.S, Atlas Geoambiental Municipal de Agudo-RS. Santa Maria: UFSM, CCNE, 2010.

BERTALANFFY, L. V. Teoria dos Sistemas. Rio de Janeiro: Fundação Getúlio Vargas, 1976.

CABRAL, T.L. Zoneamento e mapeamento geoambiental no município de Sorriso - MT. Dissertação apresentada ao Programa de Pós-graduação em Geografia e Geociências, Área de concentração em Meio Ambiente, Paisagem e Qualidade Ambiental da Universidade Federal de Santa Maria (UFSM, RS), como requisito para obtenção do grau de Mestre em Geografia, 2014.

CALDERANO FILHO, B; POLIVANOV,H.; BARROSO,E.V; GUERRA,A.J.T; CHAGAS,C. S.; CALDERANO,S.B.; CARVALHO JÚNIOR,W. Cartografia geoambiental no médio alto curso do Rio Grande (RJ), subsídios ao planejamento de paisagens rurais nas montanhosas da Serra do Mar. . São Paulo, UNESP, Geociências, v. 32, n.3, p.560-576, 2013.

DE NARDIN, Dionara; ROBAINA,L.E.S. Zoneamento geoambiental do oeste do Rio Grande do Sul: um estudo em bacia hidrográfica em processo de arenização. Santa Maria, Sociedade \& Natureza, 2010.

HASENACK, H.; WEBER, E. Base Cartográfica Vetorial Contínua do Rio Grande do Sul: Escala 1:50.000. Porto Alegre: UFRGS, 2010.

http://www.cidades.ibge.gov.br/xtras/uf.php?lang=\&coduf=43\&search=rio-grande-do-sul, Acessado em 10/08/2015.

http://glovis.usgs.gov/, Acessado em 10/07/2015.

MENEZES, D. J.; SCCOTI, A.V.; ROBAINA, L. E. ;TRENTIN,R. Zoneamento geoambiental do município de São Pedro do Sul - RS. Revista Geografias,v.13, n.5 , p.68-80, 2012.

SOUZA, L. A. et al. Cartografia Geoambiental como suporte ao plano diretor de Mariana, MG. In: Congresso Brasileiro de Geologia de Engenharia e Ambiental, 11., 2005. Anais... Florianópolis: UFSC, 2005.

TRENTIN, R. Mapeamento geomorfológico e caracterização geoambiental da Bacia Hidrográfica do Rio Itu - Oeste do Rio Grande do Sul - Brasil / Romário Trentin. - Curitiba, 2011.

TRENTIN, R; ROBAINA, L. E. S. Unidades geoambientais na bacia hidrográfica do rio ltu - oeste do estado do Rio Grande do Sul, Brasil. Revista do Departamento de Geografia , v.23, n.3, p.262-282, 2012. https://doi.org/10.7154/RDG.2012.0023.0012

\begin{tabular}{llllll}
\hline Caminhos de Geografia & Uberlândia - MG & v. 19, n. 68 & Dez/2018 & p. 200-214 Página 213
\end{tabular}


VEDOVELLO, R. Aplicações da cartografia geoambiental. In: 5 SIMPÓSIO BRASILEIRO DE CARTOGRAFIA GEOTÉCNICA E GEOAMBIENTAL. Anais... São Carlos-SP, 2004.

ZERFASS, H. Geologia da Folha Agudo, SH.22-V-C-V. (Cartas, mapas ou similares/Mapa), 2007. ZUQUETTE, L. V. Análise crítica sobre cartografia geotécnica e proposta metodológica para as condições brasileiras. São Carlos: Escola de Engenharia de São Carlos, Tese de Doutorado,1987.

ZUQUETTE, L. V. Importância do mapeamento geotécnico no uso e ocupação do meio físico: fundamentos e guia para elaboração. São Carlos: Escola de Engenharia de São Carlos, Tese de Livre Docência, 1993.

Recebido em: 14/11/2017

Aceito para publicação em: 26/09/2018 